index comunicación | no 11(2) 2021 | Páginas 165-185

E-ISSN: 2174-1859 | ISSN: 2444-3239 | Depósito Legal: M-19965-2015

Recibido el 21_12_2020 | Aceptado el 08_04_2021 | Publicado el 15_07_2021

\title{
OPORTUNIDADES DE LA \\ ROBOTIZACIÓN EN EL PERIODISMO LOCAL: EL CASO DE 'MITTMEDIA'
}

OPPORTUNITIES FOR ROBOTIZATION IN LOCAL JOURNALISM: THE CASE OF 'MITTMEDIA'

https://doi.org/10.33732/ixc/11/020portu

Rubén Rivas-de-Roca Universidad de Sevilla rrivasderoca@us.es https://orcid.org/0000-0001-5842-4533

VI Plan Propio de Investigación y Transferencia de la Universidad de Sevilla 
Resumen: El uso de la inteligencia artificial (IA) con fines periodísticos se encuentra cada vez más presente en medios de todo el mundo. La prensa local, a pesar de su centralidad en la construcción de comunidades de pertenencia, goza de un menor nivel de utilización de las potencialidades de la IA debido a su limitada capacidad económica. En este contexto, la presente investigación contempla el empleo de la robotización en los medios locales del consorcio Mittmedia en Suecia, que en el período 2017-2020 han incrementado exponencialmente su número de suscriptores a través de artículos producidos por un bot (The homeowners bot). Se analiza la estructura y contenidos de las informaciones publicadas por esta herramienta de United Robots, para lo que se recogen 50 piezas publicadas en tres períodos de tiempo $(2017,2018$ y 2019). Como resultados se observa que el bot produce textos reducidos con elementos de interactividad que contextualizan su contenido. La automatización se focaliza en las noticias del sector inmobiliario, proporcionando una información de servicio público mediante suscripción. Esta práctica abre la puerta a que la robotización sea empleada para elaborar textos que generen fidelización en espacios locales, ya que sin la IA estos asuntos quedarían sin cubrir.

Palabras clave: inteligencia artificial; robotización; periodismo hi-tech; medios locales; modelos de negocio; fidelización de audiencias.

Abstract: The use of artificial intelligence (AI) for journalistic purposes is increasingly present in worldwide media. Despite its key role in the construction of communities, the local press enjoys a lower level of use of AI due to its limited economic capacity. It is in this context that this research examines the use of robotization in the local media of the Mittmedia consortium in Sweden, which in the period 2017-2020 have exponentially increased their number of subscribers through articles produced by a bot (The homeowners bot). The structure and content of the information published by this United Robot tool is analyzed, for which 50 news items published in three periods of time (2017, 2018 and 2019) are collected. As a result, it is observed that the bot produces short texts with interactivity elements that contextualize their content. Automation focuses on news from the real estate sector, providing public service information by subscription. This practice means a chance for robotization to be used to develop texts that generate engagement in local areas, since without AI many of these issues would be left uncovered.

Keywords: Artificial Intelligence; Robotization; Hi-Tech Journalism; Local Media; Business Models; Audience Engagement. 


\section{Introducción}

Las tecnologías digitales han transformado la forma de hacer periodismo en las últimas décadas, en un proceso que se ha acelerado con la consolidación de Internet como instrumento de uso diario (Salaverría, 2019). Los móviles se erigen en la principal fuente de recepción de noticias en numerosos países (Newman et al., 2020), lo que impulsa consumos más participativos, que exigen de perfiles profesionales ajustados a la demanda de la audiencia (López-García, Rodríguez-Vázquez y Pereira-Fariña, 2017; Thurman, Dörr y Kunert, 2017).

Una de las principales innovaciones tecnológicas en el periodismo es el uso de la inteligencia artificial (IA), interpretada como el culmen de la automatización en el proceso informativo (Cervera, 2017; Diakopoulos, 2019). La IA se define como la implantación de mecanismos informáticos que efectúan, mediante algoritmos, tareas llevadas a cabo hasta entonces por humanos (Barrat, 2013). Su aplicación al periodismo tiene lugar gracias al trabajo de profesionales de la información, que nutren estos sistemas para generar informaciones automáticas a partir de una programación previa (Anderson, 2013; Ufarte Ruiz y Manfredi Sánchez, 2019).

La aparición de la IA en la información ha causado un gran interés en la academia, que se refiere a este fenómeno con términos dispares, tales como «periodismo automatizado» (Caswell y Dörr, 2018), «periodismo computacional» (Vállez y Codina, 2018) o «robotperiodismo» (Carlson, 2015). Esta última definición encaja con el empleo de bots con fines informativos, convertido en práctica creciente en las áreas de deportes y finanzas (Dörr, 2016; Lemelshtrich, 2018). La utilización de estos robots es todavía experimental, pero los primeros estudios acerca del deporte señalan que la IA mejora las coberturas periodísticas al reducir las tareas sin valor añadido de las que se deben encargar los reporteros (Rojas Torrijos, 2019).

Sin embargo, los análisis sobre este periodismo robotizado o hi-tech suelen venir acompañados de un debate relativo a sus riesgos implícitos. Existen críticas a la calidad de los textos producidos (Murcia Verdú y Ufarte Ruiz, 2019), así como dudas éticas, fruto de la nueva relación informativa entre humanos y máquinas que conlleva esta tecnología (Lewis, Guzman y Schmidt, 2019). El fuerte componente moral del trabajo periodístico, unido a su constante precarización, coaptan la percepción de los profesionales sobre las posibilidades de la robotización.

Por otro lado, se observan incertezas en el panorama digital que trascienden de la automatización informativa. La capacidad de las noticias móviles para aumentar los conocimientos políticos de la ciudadanía es incompleta (Ohme, 2019). Por tanto, la elevada interconectividad del público 
no repercute en una mayor participación social. Además, publicaciones recientes (Steensen, Ferrer-Conill y Peters, 2020) ponen en cuestión el grado de compromiso informativo de la audiencia, puesto que la información cuantitativa empleada para ese fin carece de la suficiente validez. El estudio de audiencias del periodismo digital requiere de paradigmas disruptivos, como también lo hace la robotización informativa al alterar el tradicional flujo de las noticias (Lewis, Guzman y Schmidt, 2019).

El periodismo local supone una de las especializaciones más vinculadas a su público, debido a que desempeña un rol central en el contexto informativo más próximo al ciudadano (Nielsen, 2015). Internet no ha disminuido el valor de las historias locales, sino que incluso ha incrementado su importancia (Rivas-de-Roca, García-Gordillo y Caro-González, 2020), dado que el público necesita conocer más que nunca lo que ocurre en su espacio geográfico más cercano. La información de proximidad conecta con la idea de servicio público atribuida al periodismo (Jenkins y Nielsen, 2020), que adquiere particular vigencia en estos eventos informativos que afectan directamente a la ciudadanía.

Se da la circunstancia de que algunos de los campos habituales de los medios locales, como la información meteorológica, el mercado inmobiliario o el tráfico, poseen unas características de rutinización propensas a la automatización (Coddington, 2015; Williams, Harte y Turner, 2015). Estos rasgos consisten en una frecuencia de actualización constante y en su necesidad de conocimiento por parte de la audiencia para manejarse en su entorno cercano, lo que entronca con la producción masiva de textos periodísticos de bajo coste en los que la rapidez actúa como un factor primordial (van Dalen, 2012).

Los temas anteriores son vitales para la audiencia y no exigen de una labor creativa por parte del periodista. En consecuencia, la robotización de la información sobre estas temáticas puede ser de gran interés para las empresas informativas. Los estudios hasta la fecha, basados en métodos como la observación participante o la encuesta, hallan que el público apenas percibe diferencias entre las piezas elaboradas por robots y aquellas realizadas por humanos (Napoli, 2012; Murcia Verdú y Ufarte-Ruiz, 2019). A ello se suma que la IA posibilita unos niveles muy elevados de precisión, pudiendo contribuir a una mayor confianza de la audiencia según datos del Digital News Report 2017 (Newman et al., 2017), que sostenía que el 54\% del público optaba por las noticias automatizadas por encima de las tradicionales. Esto redunda en apoyo económico al medio a través de suscripciones, que se sustentan en el concepto de «propuesta de valor» (Marín Sanchiz y Carvajal Prieto, 2019). 


\section{Inteligencia artificial y medios locales}

La automatización en la redacción de textos es una posibilidad tecnológica desde los años 90. Sin embargo, las primeras aportaciones académicas sobre la aplicación de la IA en el periodismo no se producen hasta una década después (Kim et al., 2007; Matsumoto et al., 2007). Es en el año 2014 cuando se inicia su uso real, de la mano de Los Angeles Times y un bot (Quakebot) dedicado a redactar noticias sobre movimientos sísmicos (Flores-Vivar, 2018). También en 2014 la agencia internacional Associated Press comenzó a utilizar el software Wordsmith para elaborar piezas sobre las ganancias empresariales (Dörr, 2016).

Entre 2015 y 2016, medios y agencias de prestigio de Estados Unidos incorporan el uso de la IA (Lichterman, 2017). The Washington Post la emplea para deportes y finanzas, mientras que The New York Times o Reuters lo hacen solo para contenido deportivo. La introducción de esta tecnología trasciende pronto de los Estados Unidos, con ejemplos pioneros en Europa como The Guardian en Reino Unido (Gani y Haddou, 2014), Le Monde en Francia (Sánchez Gonzales y Sánchez González, 2017) o la radiotelevisión pública $R B B$ en Berlín, que facilita datos sobre los movimientos poblacionales de la región.

La automatización está modificando singularmente la forma de trabajo de las agencias de noticias, cuya materia presenta facilidades para ser robotizada (Fanta, 2017). De acuerdo con un artículo reciente, «[...] 16 medios, 13 agencias y 21 empresas lideran a nivel mundial el escenario de la automatización de noticias» (Túñez-López, Toural-Bran y Cacheiro-Requeijo 2018: 753), entre los que se hallan las principales agencias europeas de información. El gigante tecnológico Google es una de las empresas que más trabaja sobre la robotización informativa, lo cual puede suponer un riesgo para la independencia periodística (Whittaker, 2018).

En cualquier caso, buena parte de las iniciativas de automatización de noticias proceden de startups, situadas al margen de medios y multinacionales (Ufarte-Ruiz y Manfredi Sánchez, 2019). Algunos ejemplos son Aexea, Retresco o Text-on en Alemania, Automated Insights, Linguastat o Narrative en Estados Unidos, Arria en Reino Unido o United Robots en Suecia, que supone el objeto de estudio de la presente investigación. La empresa sueca colabora con el consorcio mediático Mittmedia, manteniendo sinergias con el mercado periodístico.

Por su alto nivel de especialización, el uso de la IA se inició en grandes medios de Estados Unidos, aunque también redacciones de medios pequeños en ese país tardaron poco en recurrir a sus posibilidades. Local labs, Hoodline y Hereford Times (Lindén, 2017; Wang, 2018) han utilizado algoritmos para tratar sucesos y cuestiones de servicio público. Por su parte, en Reino Unido la 
$B B C$ cuenta con el software Salco (Semi-Automated Local Content) para coberturas locales, aplicado por sus divisiones territoriales: $B B C$ English Regions, BBC Scotland, BBC Wales y BBC Northern Ireland.

Reino Unido constituye una muestra de revitalización de la información local gracias a la digitalización (Williams, Harte y Turner, 2015), impulsando un incipiente mercado de piezas hiperlocales que satisfacen los intereses más directos de la ciudadanía. Autores como Firmstone y Coleman (2014) consideran que esta era de la información de proximidad puede perfeccionar el funcionamiento de las democracias de cercanía. El interés británico por este periodismo explica que la agencia Press Association lanzara, con financiación de Google digital news initiative, un proyecto piloto (Reporters and data robots) en los años 2018 y 2019, para que 35 medios de proximidad de este país produjeran contenidos locales e hiperlocales automatizados (Túñez-López, Toural-Bran y Valdiviezo-Abad, 2019).

Lecompte (2015) sostiene que la robotización se ajusta a la perfección a los medios locales, ya que informar mediante datos estructurados haría posible reducir costes y mejorar la precisión de sus piezas. Como se citó anteriormente, los asuntos demandados por los ciudadanos en su configuración informativa de la proximidad poseen especificaciones propicias para la automatización. Temáticas como el tráfico o el tiempo ayudan al público a conocer el estado de su localidad sin necesidad de creatividad periodística (Wang, 2018).

Aproximaciones preliminares acerca de la recepción de las noticias automatizadas como la de Clerwall (2014) revelan que el público no percibe diferencias entre textos generados por humanos y máquinas. Otro trabajo pionero, en este caso llevado a cabo por Karlsen y Stavelin (2014), señala que la inteligencia artificial en el periodismo mantiene los roles tradicionales asignados a la profesión, a la vez que no aumenta la eficiencia de los textos. Esta crítica imbrica con el hecho de que la automatización se ha limitado hasta ahora a que los informadores alimenten de datos a máquinas. El problema radica cuando el robot asume un rol habitualmente humano (Guzman y Lewis, 2020), lo que cambia la concepción del propio periodismo.

Este periodismo global y hi-tech, siguiendo la denominación de Lemelshtrich (2018), es objeto de numerosas aportaciones sobre sus oportunidades y riesgos (Diakopoulos, 2019; Murcia Verdú y Ufarte Ruiz, 2019). Hay cierto consenso en torno a que las noticias automatizadas implican peligros éticos derivados de que los robots no tienen valores (Guzman y Lewis, 2020), a los que se suma una baja calidad de los textos debido al insuficiente contraste de fuentes y la falta de interpretación (Ufarte Ruiz, Fieiras-Ceide y Túñez-López, 2020). 
Frente a las dificultades que entraña la robotización informativa, van Dalen (2012) prioriza las oportunidades que brinda. Entre ellas destacan la cobertura de eventos antes olvidados, la posibilidad de incrementar la calidad informativa de los textos humanos para diferenciarse de los producidos por bots o el mayor tiempo para la reflexión al liberar de cargas tediosas a los informadores. Broussard (2015) considera que el periodismo de investigación en profundidad se ve reforzado por la introducción de la IA en las redacciones, puesto que disminuye las actividades sin valor añadido realizadas por humanos.

Más allá de debates éticos y profesionales, la automatización es una tendencia creciente en el periodismo, siendo la audiencia joven la más favorable a este tipo de noticias (Newman et al., 2020). Los periodistas deben enfatizar su aportación personal al producto informativo en esta situación de proliferación de algoritmos y bots, en tanto que la IA no va a significar la desaparición de la profesión (Ufarte Ruiz, Fieiras-Ceide y Túñez-López, 2020). Sin embargo, bibliografía reciente (Túñez-López, Toural-Bran y CacheiroRequeijo, 2018; Salazar, 2018) detecta un enorme desconocimiento entre los periodistas de la influencia que la robotización tendrá en su trabajo.

El periodismo artificial se basa en parámetros de acción informativa para que sean reproducidos por algoritmos (Hansen et al., 2017), todo ello en un sistema mediático en el que la digitalización sigue conviviendo con los medios tradicionales (Langer y Gruber, 2020). La simplificación de los procesos manuales que ha traído consigo esta inteligencia artificial, y el convencimiento de que nos encontremos todavía en etapas primigenias de sus potencialidades, abren numerosas perspectivas en la narración informativa. La dimensión social del periodismo local (Lecompte, 2015), conjugada hoy en día con su capacidad de convertirse en historias globales (Archetti, 2019), impulsan novedosos usos de la IA.

\section{Método}

En el diseño de esta investigación se opta por el método del estudio de caso, que ha sido ya empleado para examinar los atributos de cibermedios locales de interés (García Avilés y Carvajal, 2008; Rivas-de-Roca, García-Gordillo y CaroGonzález, 2020). Este método se ajusta a nuevas realidades mediáticas como la inteligencia artificial, que quiebra las diferencias entre elementos cuantitativos y cualitativos. El estudio de caso posibilita la conjunción de estrategias multimétodo, que en este artículo consisten en una revisión bibliográfica que da a conocer el estado de la cuestión (Ramírez-Montoya y García-Peñalvo, 2018), formando parte del estudio secundario, así como en un análisis de contenido. 
Además de revisar de manera crítica las aportaciones académicas sobre periodismo hi-tech y medios locales - efectuado en el apartado anterior-, esta investigación tiene como objetivo principal conocer el tipo de robotización periodística implementada por el consorcio sueco Mittmedia con su proyecto The homeowners bot. En concreto se detallan dos propósitos específicos:

1. Analizar los contenidos y la estructura de los textos automatizados.

2. Valorar la función de servicio público brindada por las piezas seleccionadas.

El primer objetivo posee una naturaleza más cuantitativa, por lo que se decide escrutar noticias robotizadas publicadas por $L T$ y $N A$, dos de los medios más importantes de Mittmedia, considerado el grupo más relevante en el mercado de la información local sueca (L'Estrade, 2018; Southern, 2019). Todos los diarios del grupo utilizan The homeowners bot, que desde su lanzamiento hasta principios de 2019 había producido más de 34.000 piezas informativas, con una media de 480 por semana.

El gran volumen de información, sumado a que una observación previa nos ha revelado que los textos mantienen un patrón en su estructura, lleva a acotar el proyecto a 50 piezas publicadas en tres períodos de tiempo (los meses de enero de 2017, 2018 y 2019) por los dos medios citados. La elección de enero se explica por criterios de segmentación, en tanto se aprecia que ese mes mantiene un volumen de información homogéneo generado por The homowners bot a lo largo del tiempo. Se trata de un momento de baja actividad política local, que parecer suplirse con una frecuencia mayor de noticias sobre el mercado inmobiliario.

Otros estudios de caso sobre el uso de bots en el periodismo muestran que las noticias, los gráficos y los tuits son los géneros y formatos más propicios para la automatización (Rojas Torrijos, 2019). Sin embargo, el empleo mediático de Twitter en Suecia resulta escaso (Newman et al., 2020), hasta el punto de que los medios de la muestra no cuentan con presencia en la red social, lo que ha obligado a dirigir este análisis a las noticias y gráficos visibles en el contenido web.

Para conocer la estructura de las informaciones se confecciona una ficha sobre los bloques que conforman el texto (tabla 1), a partir de la observación previa del patrón aplicado. Estos datos se ponen en contexto con una descripción sobre el funcionamiento del bot, que se realiza previamente en el epígrafe de resultados. 
Tabla 1. Categorías empleadas para el análisis de la estructura

\begin{tabular}{|l|l|}
\hline Bloque $\mathbf{0}$ & Título \\
\hline Bloque 1 & Lead (entradilla) \\
\hline Bloque 2 & Contextualización temporal \\
\hline Bloque 3 & Información económica \\
\hline Bloque 4 & Proyección futura \\
\hline
\end{tabular}

Fuente: elaboración propia.

Las categorías desarrolladas para el análisis de la estructura aluden a los datos que contiene cada uno de los bloques identificados: título, entradilla de la pieza periodística, articulación de la contextualización temporal, tipo de información brindada y posible continuidad de la noticia. De esta manera se ofrece una panorámica de la configuración de los textos basada en su orden secuencial.

Por otro lado, la función de servicio público no solo se estima en tanto en cuanto la robotización se pone al servicio de los lectores locales, sino también en relación con su innovación. Con este fin se aplica la variable interactividad, medida a través de dos indicadores: hipertexto y presencia de transmedia. El hipertexto constituye una característica ya clásica del periodismo digital, basada en la ampliación de información mediante hipervínculos (García de Torres y Pou Amérigo, 2003), que se ha visto agudizada por el actual consumo en dispositivos móviles (Canavilhas, 2021), mientras que el transmedia se refiere a la construcción narrativa a través de diversos formatos (Scolari, 2013).

Siguiendo lo anterior, se crea la variable cualitativa "valor añadido", referente a una función de servicio público que aúna la producción de información original con el empleo de técnicas innovadoras que conecten mejor con la audiencia. Esta variable es abordada en las conclusiones como resultado del estudio de casos aplicado.

\section{Resultados}

Según el propio conglomerado Mittmedia (L'Estrade, 2018), The homeowners bot es una creación de United Robots, reconocida empresa líder en la automatización de noticias en los países escandinavos. United Robots está participada por tres grandes socios: el propio Mittmedia como editorial, la empresa Menmo, encargada de las labores tecnológicas, y Sören Karlsson, en la faceta de gestión de ventas.

\subsection{Contextualización de resultados (funcionamiento del bot)} United Robots cuenta con una plataforma de automatización de noticias desde el año 2017, que los redactores de los medios de Mittmedia utilizan para los 
textos robotizados. El bot (The homeowners bot) se ocupa de elegir el enfoque que va a adoptar el texto, evaluando los datos de la propiedad inmobiliaria extraídos del registro de la propiedad de Suecia (Läntmateriet). Con esa información el bot escoge una perspectiva y escribe el título de la pieza. A continuación, la máquina redacta sobre una plantilla que Mittmedia no comparte, de ahí que se pretenda ofrecer más detalles en torno a la estructura que adoptan las noticias.

Por su parte, las informaciones de The homeowners bot siempre recurren a imágenes para tratar de implicar al lector. Las fotografías de propiedades inmobiliarias que se referencian proceden de Google street view. El bot aplica un algoritmo en colaboración con Google para saber el contenido de la imagen y discernir de este modo si es la más apropiada para ilustrar la noticia. Mittmedia utiliza un enfoque de eficiencia en esta automatización (Jacobsen, 2019), que habilita escribir piezas breves de cada uno de los movimientos inmobiliarios en sus comunidades locales, un trabajo que sería imposible de abordar por los redactores.

Mittmedia es una compañía de gran tamaño, que abarca 28 periódicos y más de 20 marcas informativas locales. En otoño de 2016 la empresa lanzó su último modelo de contenido de pago cimentado en la suscripción. No era la primera vez que establecía un muro de pago, pero en esta ocasión introdujo un factor diferencial con un periodismo de datos ejercido por The homeowners bot (L'Estrade, 2018). La innovación estriba en proveer un contenido único a los lectores basado en datos, que en este caso se recaban del registro de la propiedad sueco.

\subsection{Estructura de las piezas informativas}

Se recogen 25 textos publicados por LT (Länstidningen i Södertälje) y otros 25 en NA (Nerikes allehanda). Se trata de dos diarios locales de Mittmedia que tienen en común una dilatada trayectoria, pues ambos fueron fundados en el siglo XIX. NA cubre periodísticamente la región de Örebro, situada en el centro de Suecia, mientras que $L T$ lo hace de la ciudad de Södertälje, perteneciente a la región de Estocolmo.

A pesar de diferir en las áreas geográficas objeto de la información, los textos originados por The homeowners bot presentan un orden similar. La tabla 2 expone el tipo de contenido que rellena cada uno de los bloques de la plantilla construida en la tabla 1. 
Tabla 2. Estructura de la plantilla de noticias automatizadas

\begin{tabular}{|c|l|l|}
\hline Bloque 0 & Título & $\begin{array}{l}\text { Valor monetario del movimiento (adjetivo } \\
\text { calificativo o cifra) + localización geográfica. }\end{array}$ \\
\hline Bloque 1 & Lead (entradilla) & $\begin{array}{l}\text { Datos técnicos de la vivienda + información } \\
\text { personal de los propietarios. }\end{array}$ \\
\hline Bloque 2 & $\begin{array}{l}\text { Contextualización } \\
\text { temporal }\end{array}$ & Fecha de la transacción inmobiliaria. \\
\hline Bloque 3 & $\begin{array}{l}\text { Información } \\
\text { económica }\end{array}$ & Valor monetario (vivienda y metros cuadrados). \\
\hline Bloque 4 & Proyección futura & $\begin{array}{l}\text { Puesta en contexto con otros movimientos de la } \\
\text { zona que permiten interpretar la evolución futura } \\
\text { del mercado. }\end{array}$ \\
\hline
\end{tabular}

Fuente: elaboración propia.

La plantilla obtenida tras el análisis de la muestra manifiesta una estructura concisa y claramente periodística. Al título le sigue una entradilla (lead) que sintetiza lo más sustancial de la información, haciendo referencia a datos técnicos de la vivienda y a la identidad de los propietarios. Esta alusión a aspectos personales encaja con los rasgos del periodismo de proximidad, en el que profesionales y receptores conviven en un espacio de conocimiento mutuo (Nielsen, 2015).

Tras la entradilla se expone el contenido del texto, dividido en tres bloques. Un primero con la fecha de la transacción inmobiliaria, que consideramos como una contextualización temporal; un segundo referente al valor monetario de la vivienda, compilando el precio del metro cuadrado en la zona; y un tercero y último que cuenta otros movimientos inmobiliarios que ha habido en esa área geográfica en los últimos años, favoreciendo la contextualización de la información, así como realizar proyecciones futuras sobre la evolución del mercado.

El contenido de las noticias revisadas del bot se centra en transacciones de compraventa del sector inmobiliario. Se informa de cuánto han pagado por su vivienda los vecinos, a la vez que se revela la identidad de quiénes son los integrantes de la comunidad local. Por tanto, la información es netamente localista, satisfaciendo las necesidades periodísticas más próximas del ciudadano. The homeowners bot redacta artículos de cada propiedad vendida, lo que explica su elevado volumen de piezas.

La estructura de los textos robotizados de $L T$ y $N A$ aplica la plantilla recogida en la tabla 2 en cuanto al orden de la información. Sin embargo, los bloques de contenido no siempre aparecen en los mismos párrafos. Como se observa en los ejemplos de la imagen 1, la información en ocasiones se organiza en un único párrafo, mientras que otras veces lo hace en varios. Además, la noticia de $N A$ en la imagen 1 titula con cifras monetarias el valor de la 
transacción inmobiliaria, mientras que la pieza de $L T$ prefiere un adjetivo calificativo.

Figura 1. Noticias automatizadas publicadas por NA y LT el 25 de enero de 2018

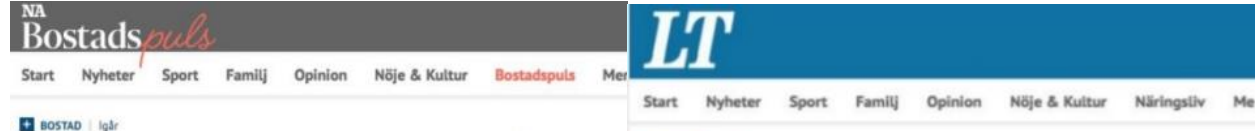

\section{0 kronor för stor villai Örebro}

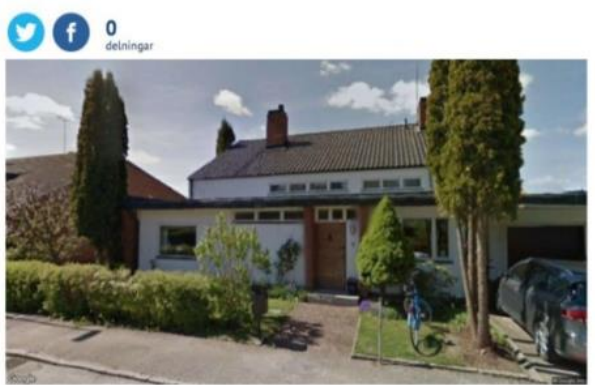

Försallijningen av fastigheten på Femkampsgatan 12 i Orebro är nu klar. Nya ăgare ăr Gunilla Kristina och Per Marcus Andersson, 40 och 43 âr, och salljare ăr Agnes Katarina Palm och Dan Börje Kvarnlof. Huset byggdes 1958 och har en boyta på 244 kvadratmeter. Ägarbytet blev klart i december 2017 och priset blev 7300000 kronor.

Mittmedias Textrobot

\section{Ny ägare till hus i Järna}

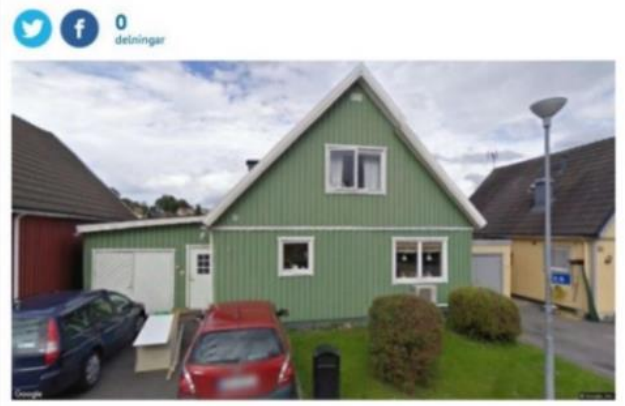

Anna Märtha Sundin, 51 âr, har köpt huset pâ adressen Vallmostigen 49 i Järna av säljaren Gun Margareta Sundin. Köpesumman blev 1300 ooo kronor och den nya ägaren tog ōver huset i november 2017. Huset är 109 kvadratmeter stort och byggdes 1970 .

Nyligen saldes ett annat hus i närheten, pa Mólnbovaligen 16. Där blev priset för det 134 kvadratmeter stora huset 3400000 kronor.

Fuente: NA (Nerikes allehanda) y LT (Länstidningen i Södertälje).

La alternancia de contenidos en el título y los cambios en la estructuración de los párrafos son una constante en la muestra de 50 noticias. Esto significa que el bot es capaz de elaborar textos con una cierta pluralidad discursiva, dentro de unas pautas de brevedad y sencillez. Esta modalidad de recurso periodístico puede catalogarse de tradicional, ya que contiene únicamente texto y fotografía. El uso de la IA se limita a seleccionar el enfoque, automatizar la redacción mediante una plantilla y escoger con un algoritmo la imagen que mejor se ajusta a la información.

Mittmedia no esconde la utilización de un bot en sus noticias sobre el sector inmobiliario. Todas las unidades informativas inspeccionadas tienen un pie de página que indica que han sido redactadas por un robot para textos que pertenece a la compañía. Esta transparencia denota cómo The homeowners bot es una herramienta distintiva para Mittmedia, que consigue con ella producir noticias constantes en torno a datos del registro de la propiedad sueco. 


\subsection{Innovación del servicio público de la información local}

El hecho de informar de cada una de las transacciones inmobiliarias que suceden en los espacios geográficos de Mittmedia, suministrando datos sobre el precio, la vivienda y los compradores, cumple una función pública en las comunidades locales. En estas áreas las necesidades de la audiencia se dirigen a quehaceres del día a día, como la compraventa de edificios o el hecho de cuál es la identidad de los vecinos.

La robotización efectuada por Mittmedia obedece a una labor que, por su volumen y alto procesamiento de datos, resultaría inabarcable para redactores humanos. No obstante, en la era digital la interactividad supone asimismo un valor público, en tanto que consigue involucrar a la audiencia. Las 50 noticias de la muestra, unidas a la observación frecuente de los textos automatizados de $N A$ y $L T$, revelan la ausencia de hipertexto y estrategias transmedia. Destaca la no utilización de hipertexto, es decir, de referencias documentales a otro contenido web, una de las prácticas primigenias del periodismo digital (Salaverría, 2019).

Tampoco se aprovechan las potencialidades del transmedia, que poseen la cualidad de contribuir a la visualización de la información, de peculiar interés en una sociedad que busca cada vez más contenidos multiplataforma (Scolari, 2013; Serrano Tellería, 2016). A pesar de que según Mittmedia el 68\% de sus lectores no percibe que las noticias de The homeowners bot hayan sido producidas por un robot (Jacobsen, 2019), la asimilación entre periodistas y máquinas no es empleada para instituir fórmulas visuales de consumo de la información.

El componente geográfico del sector inmobiliario hace que sea un tema proclive a los mapas. Sin embargo, el bot restringe su acción a la de un informador tradicional con ingentes cantidades de datos procedentes de las administraciones públicas. Las piezas cuentan únicamente con textos e imágenes, teniendo interfaces clásicas en comparación con las posibilidades actuales de la Red.

La escasa innovación no ha sido óbice para que las noticias producidas por el bot obtengan los mayores índices de lectura tras el muro de pago de los medios locales, hasta el extremo de que duplican al redactor más leído, si bien la cantidad de textos automatizados es mucho mayor de la que pudiera producir cualquier periodista humano. De acuerdo con informes especializados (L'Estrade, 2018; Southern, 2019), las noticias robotizadas de Mittmedia consiguieron más de 1.000 suscriptores directos a través de su lectura entre 2017 y 2019. Esta capacidad de monetizar el interés por las cuestiones inmobiliarias es lo que singulariza al proyecto. 


\section{Conclusiones y discusión}

Los resultados obtenidos permiten que esta investigación cumpla su objetivo de conocer la automatización periodística desarrollada por Mittmedia con el programa The homeowners bot. Se llega además a una serie de conclusiones. En primer lugar, el contenido del bot gira en torno a todas las transacciones inmobiliarias que se producen en las regiones en las que el consorcio posee medios locales. El bot procesa datos de libre acceso referentes a la propiedad para elaborar textos que exponen tres ítems principales: coste económico del movimiento, localización geográfica e identificación.

Como segunda aportación, nuestro análisis sistemático de la muestra indica que las noticias siguen un patrón similar independientemente del contexto geográfico, dado que NA y $L T$ se adscriben a territorios diversos (rural y urbano). La estructura de los textos parece aplicar una plantilla, que cuenta con título, lead, contextualización temporal, datos económicos y proyección futura a partir de menciones a otras transacciones en la zona.

En tercer lugar, la innovación informativa derivada de la interactividad resulta pobre, sin hipertexto ni elementos transmedia. El periodismo de datos en el que se cimenta The homeowners bot no dispone en la muestra seleccionada de una presentación afín. Por tanto, el uso de la IA automatiza los textos e imágenes, sin ser empleado para diseñar formatos que plasmen un consumo más interactivo.

Por último, la información suministrada por el bot cuenta con valor añadido al ser original, narrando de manera periodística actividades de compraventa que hasta entonces no gozaban de cobertura. No lleva a cabo una innovación tecnológica en el formato, pero sí que cualitativamente resulta innovador informar de esta realidad, a lo que une que su elaboración corra a cargo de un robot. Esto provoca que los datos posean un elevado grado de precisión y transmitan valor al trabajo informativo realizado, aunque quizás podría haber sido más efectivo potenciando la citada interactividad.

Como discusión, el empleo de The homeowners bot por medios locales puede dar lugar a un debate sobre si la fidelización de suscriptores es periodística o comercial. Los textos tienen una apariencia informativa y son recogidos en medios locales con una amplia trayectoria en sus áreas geográficas. Sin embargo, el estándar de información automatizada responde a un interés comercial de los receptores por conocer la evolución del mercado inmobiliario en su zona. La prensa local pasa así a ocuparse de disciplinas que no han sido tradicionalmente periodísticas, si bien contribuyen a asegurar la supervivencia de los medios al suponer aumentos en el número de suscriptores. 
La capacidad del bot de Mittmedia como dinamizador del sector inmobiliario pone de relieve que el periodismo computacional exige de transdisciplinariedad, quebrando los antiguos esquemas de narración de los hechos (Vállez y Codina, 2018). El uso de la IA en la información conlleva también un cambio en el rol de los medios, que en este caso pasan a tener una misión más comercial que periodística. Existen profundas discusiones sobre el papel desempeñado por profesionales y máquinas en las redacciones, que afecta al propio valor futuro del periodismo (Schapals y Porlezza, 2020).

El ejemplo de The homeowners bot muestra un notable incremento de los ingresos del medio mediante una automatización que posibilita abrir un nicho informativo para la empresa. Independientemente de cuestiones éticas, la bibliografía respalda la necesidad de un binomio entre robots y periodistas, en el que los profesionales deben aprovechar estos artefactos digitales que les facilitan su trabajo (Cervera, 2017). Los periodistas de Mittmedia pueden dedicarse a tareas más creativas mientras que el bot se encarga de la rutina del mercado inmobiliario, una temática que asegura a su vez el sostenimiento económico de estos medios locales.

En los últimos años se habla de que la emoción está más presente que nunca en el periodismo (Wahl-Jorgensen, 2020), aunque parezca lo contrario en informaciones basadas en datos, lo local tiene un componente emocional. El sistema de IA aquí revisado garantiza que los lectores conozcan datos de su comunidad. El giro cuantitativo que ha significado la aplicación de la inteligencia artificial en el periodismo (Coddington, 2015) se combina con asuntos capaces de suscitar interés entre la audiencia.

The homeowners bot manifiesta el valor que la información local tiene para el periodismo automatizado. La creación de algoritmos se ha erigido en la principal distinción e innovación tecnológica de startups (Usher, 2017), incluida United Robots en Suecia, con la particularidad de estar participada por un consorcio de medios locales como es Mittmedia. La robotización de noticias provoca que en las piezas informativas se acojan menos a las posibilidades del hipertexto o el transmedia,

En cualquier caso, nos hallamos todavía en estadios iniciales del uso de la IA. Los textos tomados en consideración tienen coherencia y cumplen su pretensión informativa, pero se ciñen únicamente a proporcionar información de tipo básico (texto + fotografía). Sería necesario proyectar futuras iniciativas para conocer la evolución en medios locales pioneros. Esta publicación cuenta con limitaciones muestrales derivadas del elevado volumen informativo del bot, que la repetición de un patrón de contenido ha podido corregir en cierto sentido. 
Cabe comentar que el uso de bots ha sido asociado recientemente por la opinión pública con la proliferación de noticias falsas (fake news) y fenómenos de desinformación (Waisbord, 2018), incrementados durante la pandemia de Covid-19 (Salaverría et al., 2020). Esto obliga a tomar con cautela los altos índices de confianza previos en las piezas automatizadas (Newman et al., 2017), haciendo necesario una reflexión sobre cómo se relaciona el consumo de ese tipo de piezas periodísticas con teorías actuales como la exposición incidental a las noticias, que provoca, según la literatura, una mayor tendencia al cinismo y la desconfianza política (Song, Gil de Zúñiga y Boomgaarden, 2020).

En virtud de la gran productividad de piezas noticiosas capacitada por la automatización, cobran especial relevancia los estudios que apliquen el big data para sintetizar las preferencias periodísticas. Asimismo, puede resultar de interés efectuar investigaciones sobre espacios geográficos menos proclives a la robotización, puesto que los países nórdicos ostentan el liderazgo en dicha materia. Los roles de profesionales y máquinas en las redacciones entran en una etapa de redefinición, donde las empresas informativas se enfrentan al reto de conjugar la automatización en informaciones periodísticas y comerciales. Estas últimas son posibles gracias al empleo de la IA, que ofrece interesantes posibilidades de suscripción.

\section{Referencias bibliográficas}

ANDERSON, C. W. (2013). Towards a sociology of computational and algorithmic journalism. New Media \& Society, 15(7), 1005-1021. doi.org/10.1177/1461444812465137

ARCHETTI, C. (2019). Mapping transnational journalism in the age of flows: or how I ditched "Foreign Correspondence" and the "Immigrant Press" and started to love Histoire Croisée. Journalism Studies, 20(15), 2150-2166. doi.org/10.1080/1461670X.2019.1568905

BARRAT, J. (2013). Our final invention: artificial intelligence and the end of the human era. Nueva York: Thomas Dunne Books, St. Martin Press.

BROUSSARD, M. (2015). Artificial intelligence for investigative reporting: Using an expert system to enhance journalists' ability to discover original public affairs stories. Digital Journalism, 3(6), 814-831. doi.org/10.1080/21670811.2014.985497

CANAVILHAS, J. (2021). Epistemology of mobile journalism. A review. Profesional de la Información, 30(1), e300103. doi.org/10.3145/epi.2021.ene.03 
CARLSON, M. (2015). The robotic reporter: automated journalism and the redefinition of labor, compositional forms, and journalistic authority. Digital Journalism, 3(3), 416-431. doi.org/10.1080/21670811.2014.976412

CASWELL, D. y DöRR, K. (2018). Automated journalism 2.0: event-driven narratives. Journalism Practice, 12(4), 477-496. doi.org/10.1080/17512786.2017.1320773

CerverA. J. (2017). El futuro del periodismo es ciborg. Cuadernos de periodistas, 34, 102-109. https: / / tinyurl.com/ybabwmld

Clerwall, C. (2014). Enter the robot journalist. Journalism Practice, 8(5), 519531. doi.org/10.1080/17512786.2014.883116

Coddington, M. (2015). Clarifying journalism's quantitative turn. Digital Journalism, 3(3), 331-348. doi.org/10.1080/21670811.2014.976400

DiAKOPOULOS, N. (2019). Automating the news. How algorithms are rewriting the media. Cambridge, Massachusetts: Harvard University Press.

DöRR, K. (2016). Mapping the field of algorithmic journalism. Digital Journalism, 4(6), 700-722. doi.org/10.1080/21670811.2015.1096748

FANTA, A. (2017). Putting Europe's robots on the map: automated journalism in news agencies. Oxford: Reuters Institute for the Study of Journalism, University of Oxford. https: //tinyurl.com/ycnw2h8t

FIRMSTONE, J. y COLEMAN, S. (2014). The changing role of the local news media in enabling citizens to engage in local democracies. Journalism Practice, 8(5), 596-606. doi.org/10.1080/17512786.2014.895516

FLORES-VIVAR, J. M. (2018). Algoritmos, aplicaciones y big data, nuevos paradigmas en el proceso de comunicación y de enseñanza-aprendizaje del periodismo de datos. Revista de Comunicación, 17(2), 268-291. doi.org/10.26441/RC17.2-2018-A12

GANI, A. y HADDOU, L. (2014, 16 de marzo). Could robots be the journalists of the future? The Guardian https: / / tinyurl.com/ybr9wm8b

GARCÍA AVILÉS, J. y CARVAJAL, M. (2008). Integrated and cross-Media newsroom convergence: two models of multimedia news production. The cases of Novotécnica and La Verdad Multimedia in Spain. Convergence, 14(2), 223 241. doi.org/10.1177/1354856507087945

GARcía DE TORRES, E. y Pou AMÉRIGO, M. (2003). Características de la comunicación digital. En DíAz NocI, J. y SALAVERríA, R. (COORDS.). Manual de redacción ciberperiodística (pp. 49-79). Barcelona: Ariel.

GUZMAN, A. L. y LEWIS, S. C. (2020). Artificial intelligence and communication: a human-machine communication research agenda. New Media \& Society, 22(1), 70-86. doi.org/10.1177/1461444819858691 
Hansen, M.; Roca-Sales, M.; KeEgAn, J. M. y KInG, G. (2017). Artificial intelligence: practice and implications for journalism. Nueva York: Columbia University Libraries, Tow Center for Digital Journalism. doi.org/10.7916/D8X92PRD

JACOBSEN, N. (2019, 12 de febrero). Wie ein schwedischer Verlag mit RoboJournalismus dauerhaft Digitalabonnenten gewinnt. Meedia https: / / tinyurl.com/yaag2558

JENKINS, J. y NiELSEN, R. K. (2020). Proximity, public service, and popularity: a comparative study of how local journalists view quality news. Journalism Studies, 2(2), 236-253. doi.org/10.1080/1461670X.2019.1636704

KARLSEN, J. y STAVELIN, E. (2014). Computational journalism in Norwegian newsrooms. Journalism Practice, 8(1), 34-48. doi.org/10.1080/17512786.2013.813190

KIM, J. H.; LEE, K. H.; KIM, Y. D.; KuPPUSWAMY, N. S. y Jo, J. (2007). Ubiquitous robot: A new paradigm for integrated services. En: Proceedings 2007 IEEE Intl Conf on Robotics and Automation, 2853-2858. doi.org/10.1109/ROBOT.2007.363904

LANGER, A. I. y GRUBER, J. B. (2020). Political agenda setting in the hybrid media System: why legacy media still Matter a great deal. The International Journal of Press/Politics. doi.org/10.1177/1940161220925023

LECOMPTE, C. (2015, 1 de septiembre). Automation in the newsroom. Nieman Reports https://tinyurl.com/yc6ylxpn

LEMELSHTRICH, N. (2018). Robot journalism: Can human journalism survive? Nueva York: World Scientific Publishing.

L'Estrade, L. (2018, 18 de junio). MittMedia Homeowners Bot boosts digital subscriptions with automated articles. INMA ideas blog https: / / tinyurl.com/y97nkxhc

LEWIS, S. C.; GUZMAN, A. L. y SCHMIDT, T. R. (2019). Automation, journalism, and human-machine communication: rethinking roles and relationships of humans and machines in news. Digital Journalism, 7(4), 409-427. doi.org/10.1080/21670811.2019.1577147

LINDÉN, C. G. (2017). Algorithms for journalism: The future of news work. The Journal of Media Innovations, 4(1), 60-76. doi.org/10.5617/jmi.v4i1.2420

LóPEZ-GARCÍA, X.; RodrÍGUEZ- VÁZQUEZ, A.-I. y PEREIRA-FARIÑA, X. (2017). Competencias tecnológicas y nuevos perfiles profesionales: desafíos del periodismo actual. Comunicar, 25(53), 81-90. doi.org/10.3916/C53-2017-08

MARÍn SANCHIZ, C. R. y CARVAJAL PRIETO, M. (2019). Modelos de negocio en el periodismo: una propuesta metodológica para realizar estudios de caso. Index.comunicación, 9(1), 149-171. https: / /tinyurl.com/ya6uvdo6 
MAtSUmoto, R.; NAKAYAMA, H; HARAdA, T. y KuniYOSHI, Y. (2007). Journalist robot: robot system making news articles from real world. En: 2007 IEEE Intl Conf on Robotics and Automation, 1234-1241. doi.org/10.1109/IROS.2007.4399598

MuRCia VERdú, F. J. y UfARTE RuIZ, M. J. (2019). Mapa de riesgos del periodismo hi-tech. Hipertext.net, 18, 47-55. doi.org/10.31009/hipertext.net. 2019.i18.05

NAPOLI, P. (2012). Audience evolution and the future of audience research. International Journal on Media Management, 14(2), 79-97. doi.org/10.1080/14241277.2012.675753

NEWMAN, N.; FletCHER, R.; KAlOGEROPOUlOS, A.; LEVY, D. A. y NiELSEN, R. K. (2017). Reuters Institute Digital News Report 2017. Oxford: Reuters Institute for the Study of Journalism, University of Oxford. https: / / tinyurl.com/b4et5f5f

Newman, N.; Fletcher, R.; SchulZ, A.; Andi, S. y Nielsen, R. K. (2020). Reuters Institute Digital News Report 2020. Oxford: Reuters Institute for the Study of Journalism, University of Oxford. https: / /tinyurl.com/y7sqj3ve

NIELSEN, R. K. (2015). Local newspapers as keystone media: the increased importance of diminished newspapers for local political information environments. En NIELSEN, R. K. (ED.). Local Journalism: the decline of newspapers and the rise of digital media (pp. 51-72). Londres: I.B. Tauris.

OHME, J. (2019). Mobile but not mobilized? Differential gains from mobile news consumption for citizens' political knowledge and campaign participation. Digital Journalism, 8(1), 103-125. doi.org/10.1080/21670811.2019.1697625

RAMÍREZ-MonTOYA, M.-S. y GARCÍA-PEÑALVO, F.-J. (2018). Co-creación e innovación abierta: Revisión sistemática de literatura. Comunicar, 26(54), 9-18. doi.org/10.3916/C54-2018-01

RIVAS-DE-RoCA, R.; GARCÍA-GoRDILlO, M. y CARo-GonZÁLEZ, F. J. (2020). La construcción del periodismo «localizado» en medios digitales europeos. Estudio de casos. Revista Latina de Comunicación Social, 75, 1-26. doi.org/10.4185/RLCS-2020-1414

RojAS TORRIJOS, J. L. (2019). La automatización en las coberturas deportivas. Estudio de caso del bot creado por The Washington Post durante los JJ.00. de Río 2016 y Pyeongchang, 2018. Revista Latina de Comunicación Social, 74, 1729-1747. doi.org/10.4185/RLCS-2019-1407

SALAVERRÍA, R. (2019). Digital journalism: 25 years of research. Review article. El profesional de la información, 28(1), e280101.

doi.org/10.3145/epi.2019.ene.01 
SALAVERRÍA, R.; BuSLÓN, N.; LÓPEZ-PAN, F.; LEÓN, B.; LÓPEZ-GoÑI, I. y ERVITI, M.-C. (2020). Desinformación en tiempos de pandemia: tipología de los bulos sobre la Covid-19. El profesional de la información, 29(3), e290315. doi.org/10.3145/epi.2020.may.15

SALAZAR, I. (2018). Los robots y la Inteligencia Artificial. Nuevos retos del periodismo. Doxa Comunicación, 27, 295-315. doi.org/10.31921/doxacom.n27a15

SÁNCHEZ GonZALES, H. y SÁNCHEZ GONZÁLEZ, M. (2017). Los bots como servicio de noticias y de conectividad emocional con las audiencias. El caso de Politibot. Doxa Comunicación, 25, 63-84.

doi.org/10.31921/doxacom.n25a3

SCHAPAlS, A. K. y PORLEZZA, C. (2020). Assistance or resistance? Evaluating the intersection of automated journalism and journalistic role conceptions. Media and Communication, 8(3), 16-26. doi.org/10.17645/mac.v8i3.2020

Scolari, C. A. (2013). Narrativas transmedia. Cuando todos los medios cuentan. Barcelona: Deusto.

SERRANO TElLERÍA, A. (2016). Transmedia journalism: exploring genres and interface design. Trípodos, 38, 67-85. https: / /tinyurl.com/ybx7ot2f

SonG, H.; GIL DE ZÚÑIGA, H. y BoomgaARden, H. G. (2020). Social Media News Use and Political Cynicism: Differential Pathways Through "News Find Me" Perception. Mass Communication and Society, 23(1), 47-70. doi.org/10.1080/15205436.2019.1651867

SOUTHERN, L. (2019, 12 de febrero). Robot writers drove 1,000 paying subscribers for Swedish publisher MittMedia. DigiDay. https: / / tinyurl.com/y8gekapr

SteEnSEN, S.; FERRER-CONILL, R. y PETERS, C. (2020). (Against a) theory of audience engagement with news. Journalism Studies, 21(12), 1662-1680. doi.org/10.1080/1461670X.2020.1788414

THE HOMEOWNERS BOT (2018, 25 de enero). Ny ägare till hus i Järna. LTLänstidningen i Södertälje. https: / / tinyurl.com/wb5kxme3

THE HOMEOWNERS BOT (2018, 25 de enero). 7300000 kronor för stor villa i Örebro. NA-Nerikes allehanda. https://tinyurl.com/yse395jw

THURMAN, N.; DöRR, K. y KUNERT, J. (2017). When reporters get hands-on with robo-writing: Professionals consider automated journalism's capabilities and consequences. Digital Journalism, 5(10), 1240-1259.

doi.org/10.1080/21670811.2017.1289819

TÚÑEZ-LÓPEZ, J.-M.; TOURAL-BRAN, C. y CACHEIRo-REQUEIJO, S. (2018). Uso de bots y algoritmos para automatizar la redacción de noticias: percepción y actitudes de los periodistas en España. El profesional de la información, 27(4), 750-758. doi.org/10.3145/epi.2018.jul.04 
TÚÑEZ-LÓPEZ, M.; TOURAL-BRAN, C. y VALDIVIEZO-ABAD, C. (2019).

Automatización, bots y algoritmos en la redacción de noticias. Impacto y calidad del periodismo artificial. Revista Latina de Comunicación Social, 74, 1411-1433. doi.org/10.4185/RLCS-2019-1391

UfARTE RUIZ, M. J. y MANFREDI SÁNCHEZ, J. L. (2019). Algoritmos y bots aplicados al periodismo. El caso de Narrativa Inteligencia Artificial: estructura, producción y calidad informativa. Doxa Comunicación, 29, 213-233. doi.org/10.31921/doxacom.n29a11

UFARTE RUIZ, M. J; FIEIRAS-CEIDE, C. y TÚÑEZ-LóPEZ, M. (2020). La enseñanzaaprendizaje del periodismo automatizado en instituciones públicas: estudios, propuestas de viabilidad y perspectivas de impacto de la IA. Anàlisi: Quaderns de Comunicació i Cultura, 62, 131-146. doi.org/10.5565/rev/analisi.3289

USHER, N. (2017). Venture-backed news startups and the field of journalism. Digital Journalism, 5(9), 1116-1133. doi.org/10.1080/21670811.2016.1272064

VÁLLEZ, M. y CoDINA, L. (2018). Periodismo computacional: evolución, casos y herramientas. El profesional de la información, 27(4), 759-768. doi.org/10.3145/epi.2018.jul.05

VAN DALEN, A. (2012). The algorithms behind the headlines. Journalism Practice, 6(5-6), 648-658. doi.org/10.1080/17512786.2012.667268

WAHL-JORGENSEN, K. (2020). An emotional turn in journalism studies? Digital Journalism, 8(2), 175-194. doi.org/10.1080/21670811.2019.1697626

WAISBORD, S. (2018). Truth is What Happens to News: On journalism, fake news, and post-truth. Journalism Studies, 19(13), 1866-1878. doi.org/10.1080/1461670X.2018.1492881

WANG, S. (2018, 5 de febrero). Hyperlocal news site in San Francisco is reinventing itself with an automated local news wire. NiemanLab https: / / tinyurl.com/y8hwgtzx

WHITTAKER, J. (2018). Tech giants, artificial intelligence, and the future of journalism. Londres: Routledge.

WILLIAMS, A.; HARTE, D. y TURNER, J. (2015). The value of UK hyperlocal community news. Digital Journalism, 3(5), 680-703. doi.org/10.1080/21670811.2014.965932 